OPEN ACCESS

Edited by:

María Jesús Luque Rojas,

University of Málaga, Spain

Reviewed by:

Pablo Daniel Franco Caballero,

University of Málaga, Spain

Vanessa R. Simmering,

University of Kansas, United States

*Correspondence:

Yang Liu

liuyang@zust.edu.cn

Specialty section:

This article was submitted to Educational Psychology, a section of the journal

Frontiers in Psychology

Received: 09 September 2021 Accepted: 03 November 2021 Published: 03 December 2021

Citation:

Liu Y, Ma W, Guo X, Lin X, Wu C and Zhu $T$ (2021) Impacts of Color Coding on Programming Learning

in Multimedia Learning: Moving

Toward a Multimodal Methodology.

Front. Psychol. 12:773328.

doi: 10.3389/fpsyg.2021.773328

\section{Impacts of Color Coding on Programming Learning in Multimedia Learning: Moving Toward a Multimodal Methodology}

\author{
Yang Liu*, Weifeng Ma, Xiang Guo, Xuefen Lin, Chennan Wu and Tianshui Zhu \\ School of Information and Electronic Engineering, Zhejiang University of Science and Technology, Hangzhou, China
}

In the present study, we tested the effectiveness of color coding on the programming learning of students who were learning from video lectures. Effectiveness was measured using multimodal physiological measures, combining eye tracking and electroencephalography (EEG). Using a between-subjects design, 42 university students were randomly assigned to two video lecture conditions (color-coded vs. grayscale). The participants' eye tracking and EEG signals were recorded while watching the assigned video, and their learning performance was subsequently assessed. The results showed that the color-coded design was more beneficial than the grayscale design, as indicated by smaller pupil diameter, shorter fixation duration, higher EEG theta and alpha band power, lower EEG cognitive load, and better learning performance. The present findings have practical implications for designing slide-based programming learning video lectures; slides should highlight the format of the program code using color coding.

Keywords: color coding, EEG, eye-tracking, programming learning, multimedia learning

\section{INTRODUCTION}

Each object has its own color, be it a color such as red, green, or blue, or be it colorless (i.e., white, black, or gray). A considerable amount of scientific research on color psychology has been conducted on all aspects of color. The theoretical basis of color and psychological functioning is based on the physiological model proposed by Goldstein (1942). Goldstein discussed that color naturally causes physiological reactions that manifest in emotional experience, cognitive focus, and motor behavior.

Color carries a psychologically relevant meaning, and the colors seen influence psychological functioning (Elliot and Maier, 2012). The first study on this issue (Schauss, 1979) suggested that pink reduced physical strength and aggression. Black (Frank and Gilovich, 1988) is associated with evil, death, and other negative concepts. Red is related to happiness and facilitates non-systematic cognitive processing (Soldat et al., 1997). Therefore, color can be regarded as a type of non-content visual stimulus.

According to perceptual theory, stimuli with distinguishing features, such as color, are conducive to visual search (Treisman and Gelade, 1980; Itti and Koch, 2000). Color coding impacts learners' cognitive processing as material-oriented interventions in multimedia learning. The salience of color can attract learners' attention and guide it toward the relevant visual information that designers want learners to process (Hillstrom and Chai, 2006; Jamet et al., 2008). From the 
perspective of perceptual theory, this is a bottom-up processing method that affects the learning process and learning effect through the visual design of multimedia.

In his Cambridge Handbook of Multimedia Learning, Mayer classifies color as visual signaling (Mayer, 2005a). The signaling principle, also known as the cueing principle, points out that people learn more deeply from multimedia materials when signals are added to guide their attention to the relevant elements of the material or highlight the organization of the material (Mayer, 2005a; de Koning et al., 2009).

When color coding is added to highlight the organization of learning materials, learners can obtain more information from multimedia messages. In the process of multimedia learning, learners must integrate the information conveyed through external representations into coherent mental representations. However, there is evidence that learners often need instructional support to identify correspondence and establish relationships between them (e.g., Seufert, 2003; Seufert and Brünken, 2006). Color coding is the non-lexical information added to learning materials that can attract learners' attention and promote the selection, organization, and integration of instructional elements (de Koning et al., 2009). Many studies have shown that color coding in multimedia materials facilitates learning (Jeung et al., 1997; Kalyuga et al., 1999; de Koning et al., 2007; Ozcelik et al., 2009; Jamet, 2014; Richter et al., 2016).

Many researchers have explained from the perspective of cognitive load theory that color cues can reduce learners' overall cognitive load and avoid overload, resulting in improved academic performance (Sweller, 1988; Paas et al., 2003).

Subjective measures are the most common methods used to assess cognitive processing (Mutlu-Bayraktar et al., 2019). Subjective self-reports on personal feelings can provide valuable information, but validity and corroboration problems arise (Bethel et al., 2007). Participants may not answer exactly how they feel, but in the way they believe others will answer. Furthermore, color is an implicit affective cue that seems to influence psychological functioning without people's awareness (Friedman and Förster, 2010). Thus, physiological signals help to better understand the potential responses of participants during observations.

Eye tracking data can offer valuable information about learners' cognitive processes. As a cognitive processing assessment method, it helps reveal information about the underlying cognitive processes during multimedia learning (Just and Carpenter, 1976; Antonenko et al., 2010; van Gog and Scheiter, 2010). Many studies have incorporated eye tracking measures to investigate perceptual processes as indicators of cognitive activity (e.g., Hyönä, 2010; Jarodzka et al., 2010; Park et al., 2015a,b). For instance, pupil diameter has been shown to be a sensitive measure of mental demands. Usually, the pupil dilates to meet increased task processing demands (van der Wel and van Steenbergen, 2018; Scharinger et al., 2020). Furthermore, fixation duration is related to the continuous psychological processes associated with present information (Just and Carpenter, 1976). Total fixation time is considered to be a sign of total cognitive processing engaged with fixation information (Just and Carpenter, 1980; Rayner, 1998). Therefore, fixation duration is a very useful measure of cognitive load (Holmqvist et al., 2017).

Electroencephalography (EEG) can non-invasively assess brain activity in an authentic environment. It measures the electrical activity generated by the brain through electrodes placed on the scalp. Changes in the power of neural oscillations measured with EEG are also a credible method for examining cognitive processes in multimedia learning (Antonenko and Niederhauser, 2010). EEG signals are voltage signals generated by neural activities, and these neural activities change with cognitive processes such as learning (Lin and Kao, 2018). Moreover, EEG power reflects the capacity or performance of cortical information processing. Many prior studies have used EEG to detect, estimate, or predict human brain activities (Gevins and Smith, 2003; Galán and Beal, 2012; Yoshida et al., 2014). These measurements vary with different levels of cognitive stimulation (Berka et al., 2004), which makes it a credible choice for measuring and continuously assessing cognitive load in a learning environment (Klimesch, 1999; Anderson and Bratman, 2008).

The alpha and theta changes in rhythms reflect what is happening in a subject's information processing, even if the subject is not aware of such changes or cannot express them in words (Basar, 1999; Klimesch et al., 2005). A number of researchers have shown that alpha and theta activities are the most relevant measure of task difficulty or cognitive load amidst various task demands (Penfield and Jasper, 1954; Gale and Christie, 1987; Sterman et al., 1994; Gevins et al., 1997). Beta waves have also been demonstrated to be related to perception and cognition (Singer, 1993; Haenschel et al., 2000; Wrobel, 2000). Increased beta waves have been correlated with anxious thinking.

Electroencephalography signals are non-stationary, dynamic, and non-linear time series. Many researchers have used nonlinear parametric measures to quantify EEG data (Gribkov and Gribkova, 2000). The degree of chaos in time series data can be measured using wavelet entropy (Rosso et al., 2001), sample entropy, and approximate entropy (Richman and Randall, 2000). Entropy is an accurate measure of complexity (Pincus, 1995; Chen et al., 2009), i.e., higher entropy refers to higher complexity (Parbat and Chakraborty, 2021).

Color acts as a non-conscious prime that affects psychological function in subtle ways (Bargh, 1990). Meanwhile, EEG has a high temporal resolution and has been proven to accurately reflect subtle changes that can be distinguished and quantified in a second-by-second time frame. Therefore, EEG can provide an index of the utilization of resources for the color coding effect on learners.

In the present study, we sought to determine the color coding effect on programming learning in multimedia learning. Based on the above analysis, we hypothesized that color coding is beneficial for learning. We recorded eye tracking and EEG data simultaneously to provide further insights on assessing cognitive processing. These recordings stemmed from both the central (i.e., brain) and autonomic (i.e., pupillary response) nervous systems. We focused on measuring the EEG theta, alpha, and beta frequency band power; pupil dilation; and fixation 
A

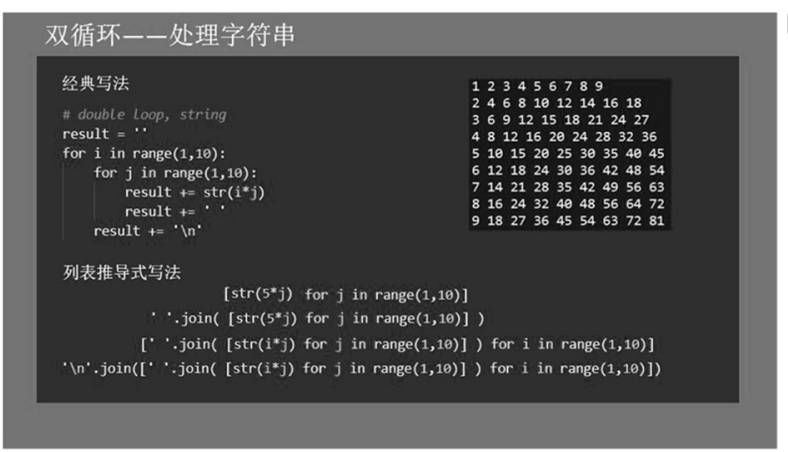

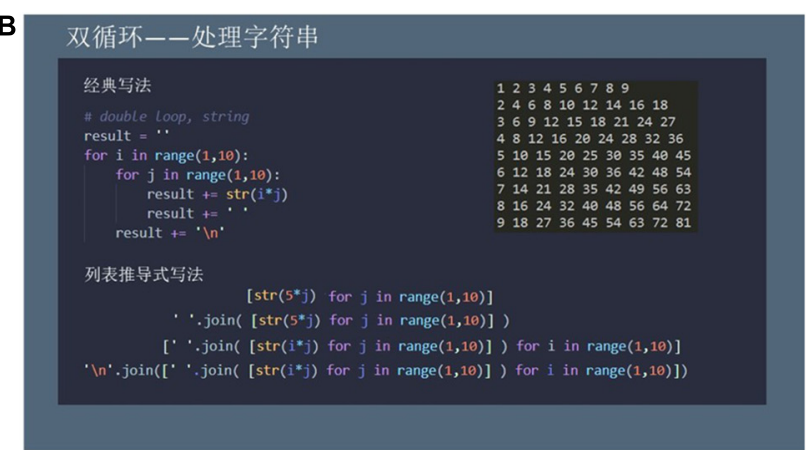

FIGURE 1 | Two slide-based video lectures in (A) grayscale design and (B) color-coded design.

duration - all of which are specific indications of cognitive processing needs.

\section{METHOD}

\section{Participants}

The participants comprised 42 graduate students recruited from the Zhejiang University of Science and Technology in China. There were 26 male and 16 female participants, all of whom were over 18 years old $(M=20.81, \mathrm{SD}=1.13)$.

The participants were selected from those who did not take the "Object-oriented Python Programming" course in order to ensure that the participants did not have any prior knowledge of the learning material. However, all participants had taken $\mathrm{C} / \mathrm{C}++$ courses to ensure that they had the necessary programming foundation. In addition, their $\mathrm{C} / \mathrm{C}++$ course scores (with a maximum possible score of 100) were used to ensure that the participants had similar prior knowledge of the learning material.

All participants had normal or corrected-to-normal vision and hearing. They signed an informed consent form before the experiment and received a small gift at the end of the study to thank them for their time and effort.

\section{Materials}

Two different versions of video lectures were used in the present study, which differed only with regard to the color of the presented text. All other features were maintained at constant values.

The learning materials are shown in Figure 1. Each video lecture included the same PowerPoint presentation, accompanied by a lecture given by a professor who is proficient in teaching the topic. As illustrated in Figure 1A, the grayscale design was achromatic. Figure 1B shows the color-coded design which used the "Palenight Theme" to highlight code format, which is widely utilized in programming. The video lectures were identical in speed, sound, and light. The materials were not self-paced and did not allow learners to start, stop, or replay short sequences. Each video lecture lasted approximately $5 \mathrm{~min}$ and introduced the topic of "List Expression in Python" in Chinese.

\section{Eye Tracking and Electroencephalography Recording}

A Tobii T120 Eye Tracker device was used to collect data regarding the participants' eye movements. The data rate of Tobii T120 for tracking was $120 \mathrm{~Hz}$. Participants completed a 9-point calibration and validation procedure before watching the video lecture. They sat in front of a 17 -inch monitor to view the lectures at a distance of $60 \mathrm{~cm}$.

Electroencephalography was recorded at 15 electrode sites (Fp1, Fp2, F7, F3, Fz, F4, F8, T7, Cz, T8, P7, Pz, P8, O1, O2), which were positioned according to the international 10-20 system (Jasper, 1958). CPz served as a reference during recording. Data were referenced to the average of all electrodes and the ground electrode was located at the AFz. The conductive gel was inserted into each electrode with a blunt needle syringe to reduce the impedance to $<5 \mathrm{k} \Omega$.

\section{Measurements}

\section{Perceptions of Task Difficulty}

The participants completed a nine-point Likert-type ( 1 = strongly easy, 9 = strongly difficult) survey on their perceptions of task difficulty, which asked the question, "How easy or difficult was the material to understand?" (Kalyuga et al., 2000). This item has been proven to be a reliable questionnaire for measuring the extraneous cognitive load experienced by learners in the learning process (Tuovinen and Paas, 2004; Kalyuga and Sweller, 2005).

\section{Individual Interest in Programming Learning}

To avoid the influence of individual interest on the experimental results, the direct measurement method was used to measure the subjects' interest in program learning. All participants were also given a nine-point Likert-type ( 1 = strongly uninterested, 9 = strongly interested) measure of their individual interest in programming learning, which asked, "How much you did like computer programming learning?"

\section{Learning Performance Test}

A learning performance test was developed to measure the acquisition of knowledge presented in the video lecture. It measured the learners' understanding of key concepts in the learning materials and their ability to apply the concepts to solve 


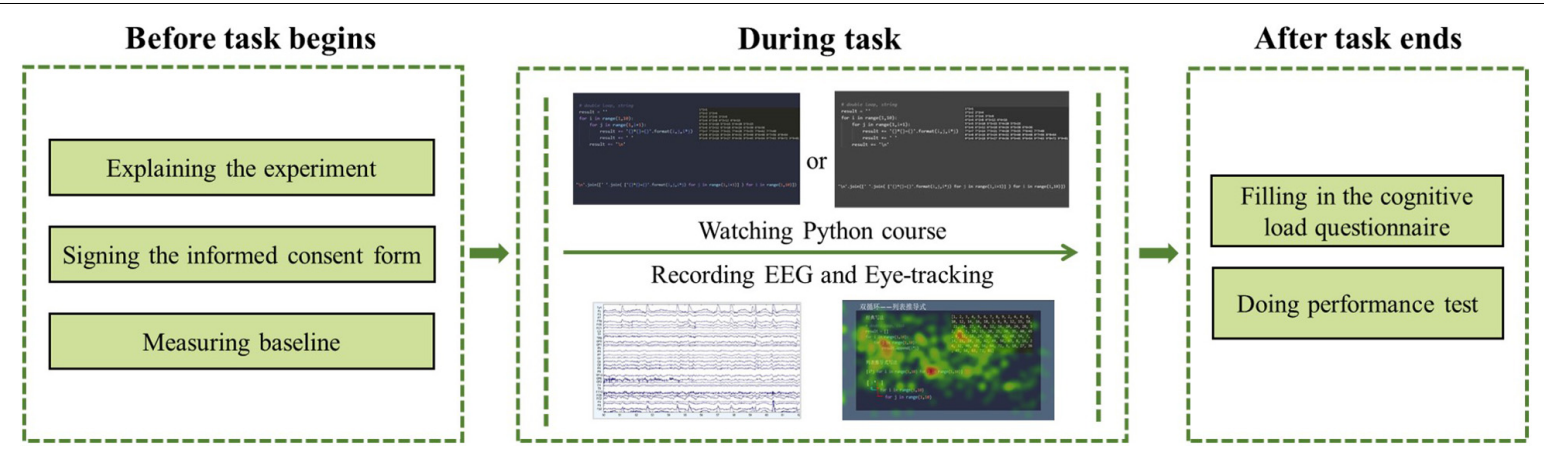

FIGURE 2 | Experimental procedure. The experiment used a between-subjects design.

problems. The test consisted of ten items and the participants received one point for each correct answer. The total possible learning performance score was 10 .

\section{Procedure}

As illustrated in Figure 2, the participants were randomly assigned to one of the two following video lecture conditions: the grayscale design condition $(n=21)$ and the color-coded design condition $(n=21)$. The procedure was conducted through computer programs and paper-and-pencil questionnaires. Each subject was individually tested in a laboratory setting for approximately $40 \mathrm{~min}$. Prior to the task, each participant learned about the experimental procedure and signed an informed consent form. The participants then closed their eyes for 3 min so we could take a baseline measurement. Thereafter, the participants viewed one of the video lectures. Participants' EEGs and eye tracking data were recorded synchronously during the entire experiment. Finally, the participants completed the cognitive load questionnaire and learning performance test immediately after viewing the assigned lecture.

\section{Data Preprocessing and Analysis}

The EEG data analysis was performed using MATLAB. Four data points were deleted for low-signal quality. Therefore, the color-coded design group included 19 data points and the grayscale design group included 19 data points.

First, the DC components were removed at $1 \mathrm{~Hz}$ using a finite impulse response (FIR) high-pass filter. Then, the other artifact noises at high frequencies were removed using an FIR low-pass filter at $50 \mathrm{~Hz}$. Subsequently, the EEG data were referenced by subtracting the average of all collected electrodes from each individual electrode. An independent component analysis was also conducted to remove electrooculography (EOG) and eye artifacts (Jung et al., 2000; Delorme et al., 2007). Finally, the Hilbert-Huang transform (HHT) technique was used to calculate the power spectrum of each EEG epoch (4s) with a frequency resolution of $0.1 \mathrm{~Hz}$ (Huang et al., 1998).

In the present study, we applied both the linear method (i.e., average power) and non-linear method (i.e., spectral entropy) on EEG data to evaluate the participants' cognitive processing.

The power of five standard EEG rhythms, i.e., delta $(0.5-4 \mathrm{~Hz})$, theta $(5-8 \mathrm{~Hz})$, alpha $(9-12 \mathrm{~Hz})$, beta $(13-32 \mathrm{~Hz})$, and gamma
(33-50 Hz), were computed by averaging the spectral powers in the corresponding frequency bands (Sghirripa et al., 2020; Pi et al., 2021). We slid the EEG data recorded in the experiment with a window size of $4 \mathrm{~s}$ to calculate the power of the five frequency bands corresponding to each window. By this means, we obtained the relative power changes of each participant in the five frequency bands during the learning process as well as the average power of all participants. For the same sliding windows, we calculated the approximate entropy value to present the pattern repeatability of the EEG time series. A larger entropy indicates less predictability.

Meanwhile, we calculated the average pupil dilation data for each trial stimulus. To synchronize with EEG features, we calculated the average of the eye tracking features in the corresponding window size (i.e., 4 s).

\section{RESULTS}

One-way analysis of variance (ANOVA) and Mann-Whitney $U$ tests were used to make comparisons across the two groups. One-way ANOVA was used on the dependent variables that met the normality assumption to conduct an ANOVA. The Mann-Whitney $U$ test was used as a non-parametric test of equivalence on dependent variables whose skewness and kurtosis values indicated that they did not meet the assumption of normality (Fritz et al., 2012; Legesse et al., 2020). The MannWhitney $U$ test is most sensitive to changes in the medium.

Effect sizes were measured by $\eta_{p}^{2}$ for the one-way ANOVA, with $\eta_{p}^{2}=0.01$ considered a small effect, 0.06 a medium effect, and 0.14 a large effect (Cohen, 1988).

Effect size were estimated by Mann-Whitney $U$ tests, the $z$ value can be used to calculate an effect size, such as the $\mathrm{r}$ proposed by Cohen (1988). Cohen's guidelines for $\mathrm{r}$ are that a large effect is 0.5 , a medium effect is 0.3 , and a small effect is 0.1 (Coolican, 2009).

\section{Control Variables}

The first step in the analysis was to determine whether there were differences in prior knowledge and individual interest between the two groups. The descriptive statistics of control variables under the two conditions are presented in Table 1. Figure 3A 
showed boxplot of subjective ratings of individual interest in the two conditions. For each variable (i.e., prior knowledge and individual interest), a one-way ANOVA was conducted with the group as the between-subjects factor. The results revealed no main effect for either control variable. For prior knowledge, $F(1,38)=0.18, p=0.67$; for individual interest, $F(1,38)=0.11$, $p=0.75$. The results indicate that there was no difference between the two learning conditions in terms of prior knowledge and individual interest.

\section{Learning Performance}

As illustrated in Table 2, the participants who studied the colorcoded video lecture had higher scores on the performance test than those who studied the grayscale video lecture. A one-way ANOVA revealed that the learning performance across the two groups was statistically significant, with $F(1,38)=5.65, p=0.028$, $\eta_{p}^{2}=0.23$, indicating that the color-coded group performed better than the grayscale group in the post-test. The effect of the material format on learning performance was found to be significant with a large effect size. This result supports our hypothesis.

\section{Subjective Ratings of Perceived Task Difficulty}

Figure 3B showed boxplot of subjective ratings of perceived task difficulty in the two conditions. The one-way ANOVA of task

TABLE 1 | Means and standard deviations for control variables.

\begin{tabular}{|c|c|c|c|c|}
\hline \multirow[b]{2}{*}{ Dependent variable } & \multicolumn{2}{|c|}{$\begin{array}{l}\text { Color-coded group } \\
\qquad(N=19)\end{array}$} & \multicolumn{2}{|c|}{$\begin{array}{l}\text { Gray-scaled group } \\
\qquad(N=19)\end{array}$} \\
\hline & $M$ & $S D$ & $M$ & $S D$ \\
\hline Prior knowledge & 80.20 & 2.82 & 80.10 & 2.14 \\
\hline Individual interest & 4.95 & 2.04 & 4.74 & 2.08 \\
\hline
\end{tabular}

difficulty scores revealed a main effect for color-coded design, with $F(1,38)=7.83, p=0.009, \eta_{p}^{2}=0.19$. As illustrated in Table 2, learners who viewed grayscale video lectures rated the difficulty of the learning material to be higher than those who received colorcoded video lectures. The results revealed that the color-coded design reduced the perceived difficulty of the learning task.

\section{Physiological Measures of Cognitive Processing Eye-Tracking Data Analysis}

The descriptive statistics of all eye-tracking variables in the two conditions are presented in Table 3. A one-way ANOVA showed that there was a significant main effect of color coding design $\left(F(1,37)=8.28, p=0.008, \eta_{p}^{2}=0.24 ; F(1,37)=5.19, p=0.031\right.$, $\left.\eta_{p}^{2}=0.13\right)$ on left and right pupil diameters. The subjects who were given the color-coded material had a smaller left pupil diameter than those who were given the grayscale material. Accordingly, the right pupil diameter was significantly larger in the grayscale condition than in the color-coded condition.

One-way ANOVA also revealed a significant difference in gaze event duration on color-coded design across experimental conditions, with $F(1,37)=4.35, p=0.047, \eta_{p}^{2}=0.143$. Participants who viewed video lectures with grayscale design had longer fixation durations than those who viewed video lectures with color-coded design.

\section{Electroencephalography Data Analysis \\ Electroencephalography Power}

The descriptive statistics of all variables of EEG power under the two conditions are presented in Table 4.

One-way ANOVA was conducted with the between-subjects factors of the color-coded design condition and delta power, theta power, alpha power, beta power, and gamma power as the dependent variables. The results are shown in Table 4 .
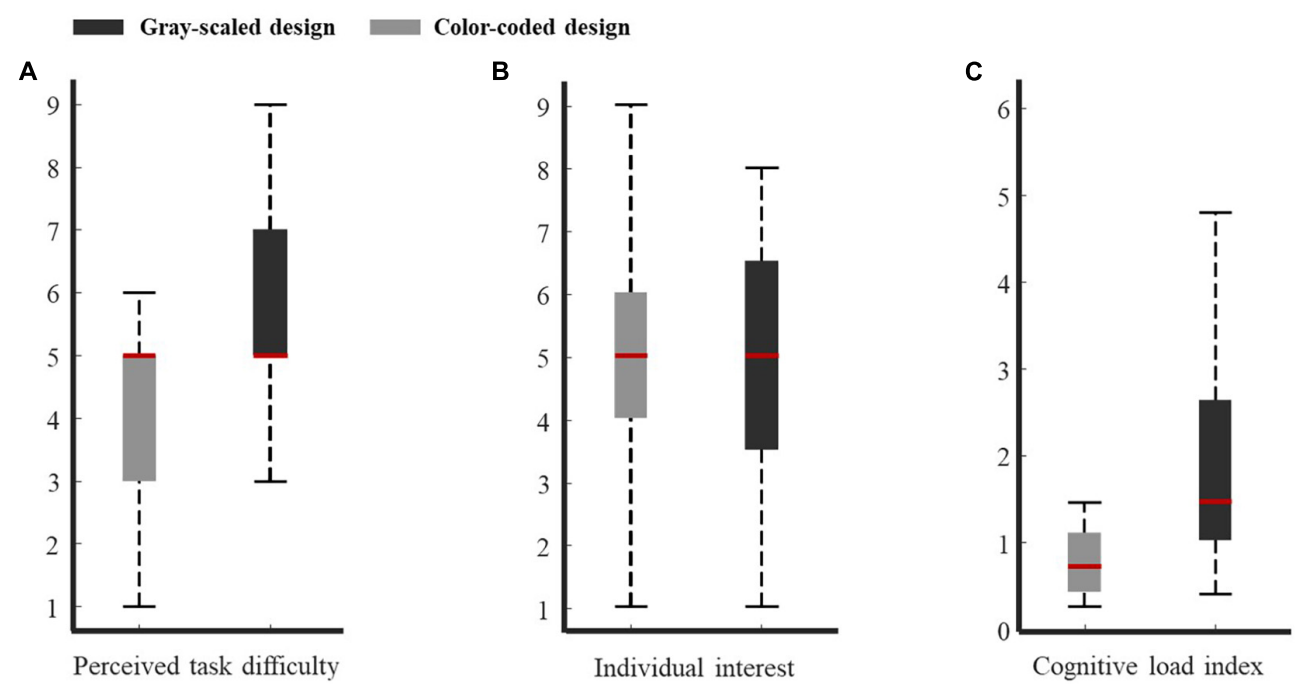

FIGURE 3 | Boxplot data for participants in two conditions. (A) Perceived task difficulty. (B) Individual interest. (C) Cognitive load. 
The one-way ANOVA revealed significant main effects of color coding $\left(F(1,37)=9.36, p=0.004, \eta_{p}^{2}=0.206 ; F(1,37)=4.43\right.$, $p=0.042, \eta_{p}^{2}=0.110 ; F(1,37)=4.89, p=0.034, \eta_{p}^{2}=0.119$; $\left.F(1,37)=4.40, p=0.043, \eta_{p}^{2}=0.109\right)$ on theta, alpha, beta and gamma power. However, there was no difference in delta power between the two learning conditions.

As shown in Table 4, the participants had higher theta and alpha power when they were shown a color-coded video lecture, and in turn had higher beta power when they were shown a grayscale video lecture.

Since the connection between EEG power and cognitive processes is more obvious in some regions than others, we further calculated the main effect of different electrodes on delta power, theta power, alpha power, beta power, and gamma power in both conditions. The results are shown in Figures 4-8.

There was no difference in the 15 electrodes on delta power across the two learning conditions (Figure 4). The participants had significantly higher theta power when learning through color-coded video lectures than through grayscale ones in all electrode regions (see Figure 5). In the Fp1, Fp2, F3, T8, $\mathrm{Cz}, \mathrm{P} 8, \mathrm{O} 1$, and $\mathrm{O} 2$ regions, the participants had significantly higher alpha power when learning through color-coded video lectures than through grayscale ones (see Figure 6). There was

TABLE 2 | Means and standard deviations of learning performance and perceived task difficulty.

\begin{tabular}{lccccc}
\hline & \multicolumn{2}{c}{$\begin{array}{c}\text { Color-coded group } \\
(\mathbf{N = 1 9 )}\end{array}$} & & \multicolumn{2}{c}{$\begin{array}{c}\text { Gray-scaled group } \\
(\mathbf{N = 1 9 )}\end{array}$} \\
\cline { 2 - 3 } \cline { 5 - 6 } Dependent variable & $\boldsymbol{M}$ & $\mathbf{S D}$ & & $\boldsymbol{M}$ & $\mathbf{S D}$ \\
\hline Learning performance & 5.09 & 2.07 & & 3.10 & 1.73 \\
Perceived task difficulty & 4.28 & 1.23 & & 5.71 & 1.76 \\
\hline
\end{tabular}

TABLE 3 | Means and standard deviations of eye-tracking variables.

\begin{tabular}{|c|c|c|c|c|}
\hline \multirow[b]{2}{*}{ Dependent variable } & \multicolumn{2}{|c|}{$\begin{array}{l}\text { Color-coded group } \\
\qquad(N=19)\end{array}$} & \multicolumn{2}{|c|}{$\begin{array}{l}\text { Gray-scaled group } \\
\qquad(N=19)\end{array}$} \\
\hline & $M$ & $S D$ & $M$ & $S D$ \\
\hline Pupil diameter left & 3.29 & 0.35 & 3.71 & 0.42 \\
\hline Pupil diameter right & 3.37 & 0.31 & 3.72 & 0.46 \\
\hline Fixation duration & 218.12 & 103.23 & 314.00 & 137.50 \\
\hline
\end{tabular}

TABLE 4 | Means and standard deviations of EEG power variables.

\begin{tabular}{|c|c|c|c|c|}
\hline \multirow[b]{2}{*}{ Dependent variable } & \multicolumn{2}{|c|}{$\begin{array}{l}\text { Color-coded group } \\
\qquad(N=19)\end{array}$} & \multicolumn{2}{|c|}{$\begin{array}{l}\text { Gray-scaled group } \\
\qquad(N=19)\end{array}$} \\
\hline & $M$ & $S D$ & $M$ & $S D$ \\
\hline Delta & 38.00 & 15.85 & 35.26 & 18.9 \\
\hline Theta & 16.12 & 5.83 & 10.70 & 5.08 \\
\hline Alpha & 16.37 & 8.60 & 11.72 & 4.36 \\
\hline Beta & 26.46 & 13.02 & 38.11 & 18.92 \\
\hline Gamma & 3.11 & 1.90 & 4.58 & 2.39 \\
\hline
\end{tabular}

a significant difference in beta power in the Fp1, F3, F7, F8, Fz, $\mathrm{F} 4, \mathrm{~T} 8$, and $\mathrm{Cz}$ regions across the two learning conditions (see Figure 7). For gamma power, the Fp1, Fp2, Fz, and F4 regions showed significant differences (see Figure 8).

We chose the regions that had significant differences and adopted $\beta /(\theta+\alpha)$ to evaluate the cognitive load. $\beta /(\theta+\alpha)$ has proven to be very effective in quantifying the state of mental workload (Berka et al., 2007). The subjects who received the grayscale learning material had a higher cognitive load $(M=2.05$, $\mathrm{SD}=1.56)$ than those who received the color-coded learning material $(M=0.96, \mathrm{SD}=0.87)$. Figure 3C showed boxplot of cognitive load in the two conditions. The Mann-Whitney $U$ test likewise revealed a significant difference across the two study conditions in cognitive load $(U=85, p=0.005, r=0.45)$. The effect of the material format on cognitive load was found to be significant, with a large effect size. This outcome indicates that the participants who viewed grayscale video lectures required more mental processing.

\section{Spectral Entropy}

The descriptive statistics of all variables of spectral entropy under the two conditions are presented in Table 5.

One-way ANOVA revealed statistically significant differences across the experimental conditions on approximate entropy $\left(F(1,37)=624.03, p<0.001, \eta_{p}^{2}=0.617\right)$, sample entropy $\left(F(1,37)=191.58, p<0.001, \eta_{p}^{2}=0.331\right)$, and wavelet entropy $\left(F(1,37)=27.31, p<0.001, \eta_{p}^{2}=0.069\right)$. The results indicated that learners who received the grayscale learning material had higher spectral entropy than those who received the colorcoded learning material. The results suggest that compared to participants who watched color-coded video lectures, the participants who watched grayscale video lectures had a heavier mental load.

\section{DISCUSSION}

The main purpose of the present study was to investigate the impact of color coding on programming learning in multimedia learning by measuring learning performance and cognitive processing using a combination of eye tracking and EEG data. The results indicated that the participants who studied the learning material with the color-coded design had higher learning performance than those who studied the learning material with the grayscale design. Our findings are in line with those of a previous study on the color coding effect (Ozcelik et al., 2009; Stark et al., 2018). Hence, we confirmed that color coding can promote programming learning in multimedia learning.

Color-coded materials minimize unnecessary search processes used to correlate verbal information, which may help improve performance. Our results show that the fixation duration on color-coded material was shorter than that on grayscale material. This indicates that participants are able to search for associated elements between visual and verbal information more quickly in the color-coded format than in the grayscale format. Utilizing the same color to relate elements in a slide could guide learners to focus on the salient and relevant information 

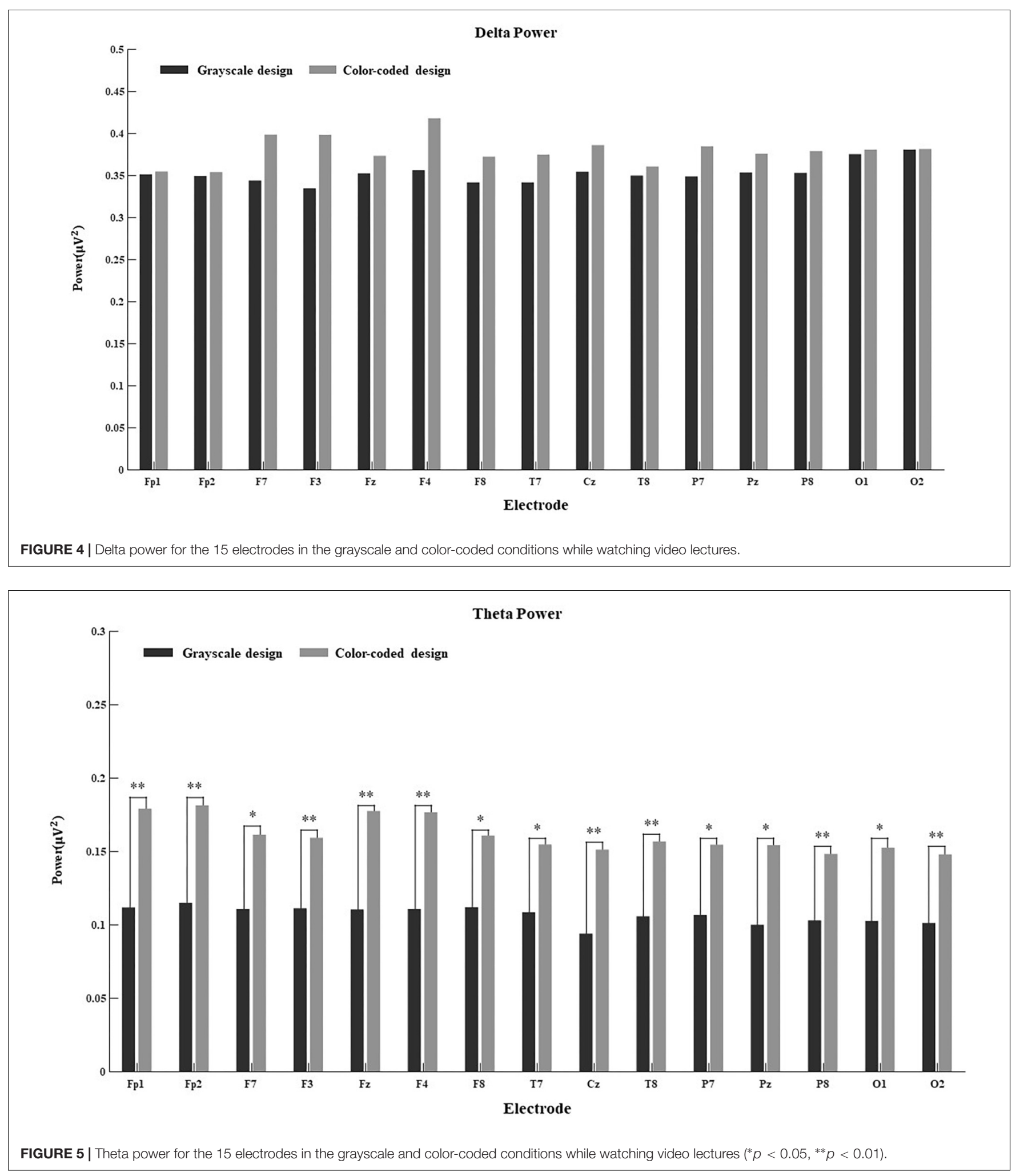

(Navalpakkam et al., 2005). This is because salient stimuli can automatically capture attention and affect the perceptual choice of subjects when processing information, so as to shorten the information search time and release more cognitive resources for information integration and material organization (Mayer, 2005b; Schnotz, 2014).

The current results are in line with the temporal contiguity effect in multimedia learning (Mayer, 2014). Our data provide 

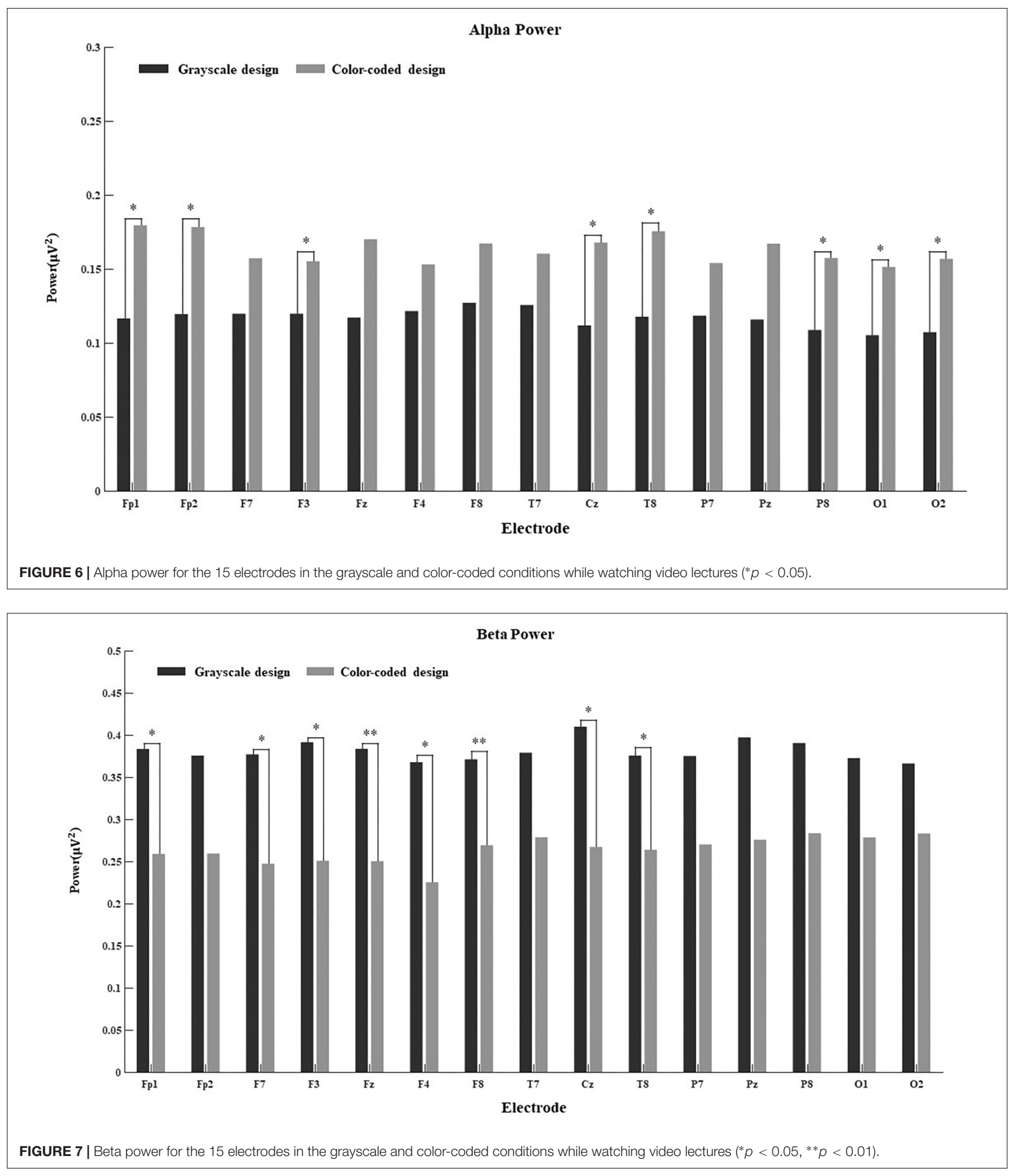

evidence that color coding helps to form an association between verbal and program code representations because the items processed timely are related to each other (Raaijmakers and Shiffrin, 1981; Kahana, 1996). Color coding facilitates the identification of corresponding visual and verbal elements, and improves learning performance through the temporal proximity of relevant information (Ginns, 2006). 


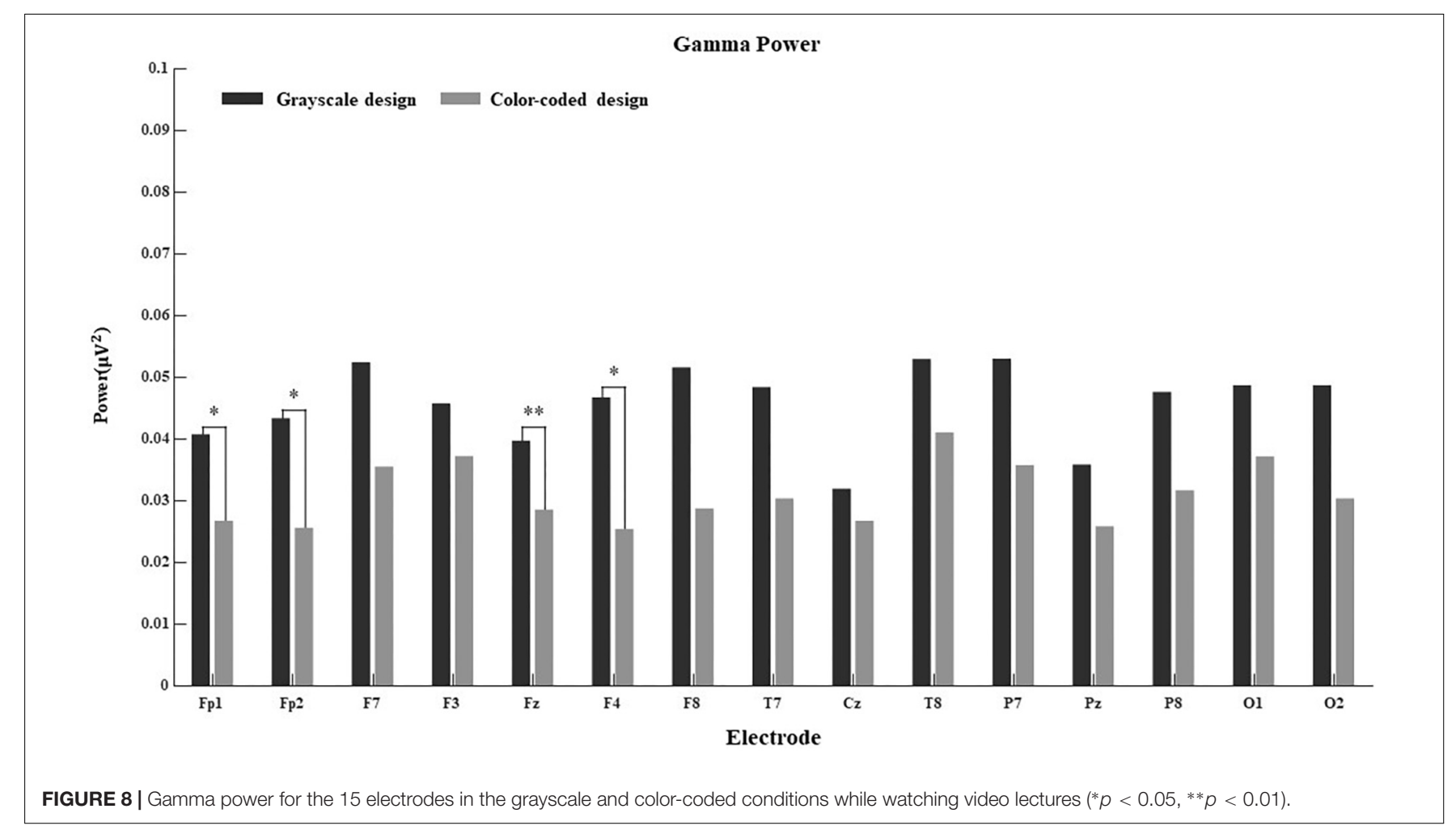

TABLE 5 | Means and standard deviations of spectral entropy variables.

\begin{tabular}{|c|c|c|c|c|}
\hline \multirow[b]{2}{*}{ Dependent variable } & \multicolumn{2}{|c|}{$\begin{array}{l}\text { Color-coded group } \\
\qquad(N=19)\end{array}$} & \multicolumn{2}{|c|}{$\begin{array}{l}\text { Gray-scaled group } \\
\qquad(N=19)\end{array}$} \\
\hline & $M$ & $S D$ & $M$ & $S D$ \\
\hline Approximate entropy & 1.19 & 0.093 & 1.44 & 0.10 \\
\hline Sample entropy & 0.60 & 0.43 & 0.66 & 0.044 \\
\hline Wavelet entropy & 2.13 & 0.019 & 2.14 & 0.018 \\
\hline
\end{tabular}

When learners are able to easily ascertain relevant information and integrate verbal and visual information, they can engage more deeply in the cognitive processing required for meaningful learning (Mayer and Chandler, 2001; Mayer and Moreno, 2003; Seufert, 2003). The present study observed higher theta and alpha powers in the color-coded learning conditions than in the grayscale learning conditions. The theta band is related to the working memory. The increases in theta oscillations are related to high working memory activity as well as successful memory encoding (Miller et al., 2018) and retrieval (Solomon et al., 2019; Pi et al., 2021). Therefore, deep processing of learning material in working memory can successfully encode memory (Khader et al., 2010; Lin et al., 2017), and working memory maintenance can forecast long-term memory (Hsieh and Ranganath, 2014). The learners who successfully memorized learning materials showed higher theta power than those who did not (Khader et al., 2010). Neural oscillations in the alpha band are related to an increase in internal attention-demanding cognitive processing (Klimesch, 2012; Fink and Benedek, 2014). Our study suggests that the color-coded group had a greater engagement of working memory and attention than the grayscale group, allowing information to be processed at a deeper level and thus resulting in better learning performance (Pi et al., 2021).

Fixation durations within the same activity can also reflect cognitive processing and cognitive load (Kruger and Doherty, 2016); a longer fixation duration suggests an increased cognitive load. Furthermore, the higher the difficulty of text comprehension and the greater the memory load during learning, the greater the pupil enlargement (Kahneman and Beatty, 1966, 1967). The results of the present study showed that the participants who viewed grayscale video lectures had longer fixation durations and greater pupil size than those who viewed color-coded video lectures. This indicated that the participants under the grayscale learning condition had a higher cognitive load than those under the color-coded condition. These results are consistent with the Cognitive Load Theory (Sweller, 1988, 1994) and the Cognitive Theory of Multimedia Learning (Mayer, 2005b). In the process of multimedia learning, learners need to psychologically integrate information transmitted through external representations into a coherent psychological representation. If learners utilize their limited cognitive resources to search the text when they hear new words in the narration, the visual scanning activity will produce extraneous cognitive processing (Paas and Sweller, 2014; Wang et al., 2020). Prior research has shown that learners usually need instructional support to identify correspondences and establish connections between them (e.g., Seufert, 2003; Seufert and Brünken, 2006). As a mode of signaling, color coding could guide learners' attention toward essential material and thereby 
eliminate the need to process irrelevant material. Color coding highlights the organization of the essential material to guide learners' cognitive processing. Specifically, it reduces extraneous mental processing demands to allow people to learn more deeply, which in turn leads to improved learning performance.

Using color coding could reduce the search for reference in the text and improve split-attention effects, resulting in lower perceived task difficulty (Ayres and Sweller, 2014; Xie et al., 2016), which is a reliable measure of extraneous cognitive load (Kalyuga et al., 2000). Subjective ratings of task difficulty increase as the extraneous cognitive load increases (Paas and van Merrienboer, 1993; Paas et al., 1994). The study results indicate that the participants in the grayscale group had more extraneous cognitive load than the participants in the color-coded group. Extraneous cognitive load is caused by the inappropriate presentation of the learning material (Sweller, 2004). When the extraneous cognitive load is increased, the germane cognitive load is reduced and learning is lessened. Learners use limited working memory resources to deal with the extraneous factors imposed by the teaching process rather than the intrinsic material. The more working memory resources are needed to deal with the extraneous cognitive load, the less resources are available to deal with the intrinsic cognitive load, which in turn reduces learning (Sweller, 2010). Meanwhile, color coding is an effective multimedia design method that minimizes extraneous overload (van Gog, 2014); it helps people study more deeply in multimedia learning because the added cues emphasize the organization of the essential material. The results indicated that the index $\beta /(\theta+\alpha)$ could measure the extraneous cognitive load during the learning process.

The results also provide evidence for the emotional design hypothesis (e.g., Mayer and Estrella, 2014; Plass et al., 2014). Making essential elements visually appealing (i.e., colored) directs cognitive processing (i.e., selecting) in the learning process by guiding attention, maintaining cognitive processing, and helping learners better understand the essential material (i.e., organizing and integrating) - thereby leading to better learning (Pekrun, 2006).

\section{CONCLUSION}

This study provides evidence for the benefits of using color coding in programming learning during multimedia learning. We utilized multimodal physiological measures to access process information for a detailed analysis of the programming learning process using color-coded design and grayscale design in

\section{REFERENCES}

Anderson, C. W., and Bratman, J. A. (2008). "Translating thoughts into actions by finding patterns in brainwave," in Proceedings of the 14th Yale Workshop on Adaptive and Learning Systems, (New Haven: Yale University).

Antonenko, P., and Niederhauser, D. S. (2010). The influence of leads on cognitive load and learning in a hypertext environment. Comp. Hum. Behav. 26, 140-150. doi: 10.1016/j.chb.2009.10.014

Antonenko, P., Paas, F., Grabner, R., and van Gog, T. (2010). Using electroencephalography to measure cognitive load. multimedia learning materials. We likewise combined EEG frequency band power data and eye tracking data to measure mental processing. The results demonstrate that color coding guides learners in finding corresponding visual and verbal information and paying attention to critical information for meaningful learning. The participants under the color-coded condition had a lower cognitive load, more positive learning experience, and better learning performance than those under the grayscale condition.

The results of the present study suggest that using color coding to highlight the format of program code in video lectures for programming learning can improve learning performance. Learning material might be better designed to help learners select relevant information and integrate verbal and visual representations so as to enhance learning (Mayer and Fiorelle, 2014). The conclusions of this study can also be extended to other courses.

\section{DATA AVAILABILITY STATEMENT}

The datasets presented in this study can be found in online repositories. The names of the repository/repositories and accession number(s) can be found below: https://github.com/ zeron21/Multimodal_Data.git.

\section{ETHICS STATEMENT}

The studies involving human participants were reviewed and approved by the Ethics Committee of the School of Information and Electronic Engineering, Zhejiang University of Science and Technology. The participants provided their written informed consent to participate in this study.

\section{AUTHOR CONTRIBUTIONS}

All authors listed have made a substantial, direct, and intellectual contribution to the work, and approved it for publication.

\section{FUNDING}

This research was supported by the Research Projects of the Humanities and Social Sciences Foundation of the Ministry of Education of China (Grant No. 20YJA880034). 
Basar, E. (1999). Brain function and oscillations. Integrative Brain Functions. Neurophysiology and Cognitive Processes. Berlin: Springer.

Berka, C., Levendowski, D. J., Cvetinovic, M. M., Petrovic, M. M., Davis, G., Lumicao, M. N., et al. (2004). Real-time analysis of EEG indices of alertness, cognition, and memory with a wireless EEG headset. Int. J. Human-Comp. Interact. 17, 151-170. doi: 10.1207/s15327590ijhc1702_3

Berka, C., Levendowski, D. J., Lumicao, M. N., Yau, A., Davis, G., Zivkovic, V. T., et al. (2007). EEG correlates of task engagement and mental workload in vigilance, learning, and memory tasks. Aviat. Space Environ. Med. 78, B231-B244.

Bethel, C., Salomon, K., Murphy, R., and Burke, J. (2007). "Survey of psychophysiology measurements applied to human-robot interaction," in Proceedings pf the IEEE RO-MAN, (Jeju Island).

Chen, W. T., Zhuang, J., Yu, W. X., and Wang, Z. H. (2009). Measuring complexity using FuzzyEn, ApEn, and SampEn. Med. Eng. Phys. 31, 61-68. doi: 10.1016/j. medengphy.2008.04.005

Cohen, J. (1988). Statistical Power Analysis for the Behavioral Sciences, 2nd Edn. Hillsdale, NJ: Erlbaum.

Coolican, H. (2009). Research Methods and Statistics in Psychology. London: Hodder.

de Koning, B. B., Tabbers, H. K., Rikers, R. M. J. P., and Paas, F. (2007). Attention cueing as a means to enhance learning from an animation. Appl. Cogn. Psychol. 21, 731-746. doi: 10.1002/acp.1346

de Koning, B. B., Tabbers, H. K., Rikers, R. M. J. P., and Paas, F. (2009). Towards a framework for attention cueing in instructional animations:guidelines for research and design. Educ. Psychol. Rev. 21, 113-140. doi: 10.1007/s10648-0099098-7

Delorme, A., Sejnowski, T., and Makeig, S. (2007). Enhanced detection of artifacts in EEG data using higher-order statistics and inde-pendent component analysis. Neuroimage 34, 1443-1449. doi: 10.1016/j.neuroimage.2006.11. 004

Elliot, A. J., and Maier, M. A. (2012). Color-in-Context theory. Adv. Exp. Soc. Psychol. 45, 61-125. doi: 10.1016/b978-0-12-394286-9.00 002-0

Fink, A., and Benedek, M. (2014). EEG alpha power and creative ideation. Neurosci. Biobehav. Rev. 44, 111-123.

Frank, M. G., and Gilovich, T. (1988). The dark side of self and social perception: black uniforms and aggression in professional sports. J. Pers. Soc. Psychol. 54, 74-85. doi: 10.1037//0022-3514.54.1.74

Friedman, R. S., and Förster, J. (2010). Implicit affective cues and attentional tuning: an integrative review. Psychol. Bull. 136, 875-893. doi: 10.1037/ a0020495

Fritz, C. O., Morris, P. E., and Richler, J. J. (2012). Effect size estimates: current use, calculations, and interpretation. J. Exp. Psychol. General 141, 2-18.

Galán, F. C., and Beal, C. R. (2012). EEG Estimates of Engagement and Cognitive Workload Predict Math Problem Solving Outcomes. UMAP 2012: User Modeling, Adaptation, and Personalization. Berlin: Springer.

Gale, A., and Christie, B. (1987). Psychophysiology and the Electronic Workplace. London: Wiley.

Gevins, A., and Smith, M. E. (2003). Neurophysiological measures of cognitive workload during human-computer interaction. Theoretical Issues Ergonom. Sci. 4, 113-131. doi: 10.1016/bs.pbr.2016.04.021

Gevins, A., Smith, M. E., McEvoy, L., and Yu, D. (1997). High-resolution EEG mapping of cortical activation related to working memory: effects of task difficulty, type of processing, and practice. Cereb. Cortex 7, 374-385. doi: $10.1093 /$ cercor/7.4.374

Ginns, P. (2006). Integrating information: a meta-analysis of the spatial contiguity and temporal contiguity effects. Learn. Instruct. 16, 511-525. doi: 10.1016/j. learninstruc.2006.10.001

Goldstein, K. (1942). Some experimental observations concerning the influence of colors on the function of the organism. Occupat. Therapy Rehabil. 21, 147-151. doi: 10.1007/BF03190881

Gribkov, D., and Gribkova, V. (2000). Learning dynamics from nonstationary time series: analysis of electroencephalograms. Phys. Rev. E-Stat. Phys. Plasmas Fluids Relat. Interdiscip. Top. 61, 6538-6545.

Haenschel, C., Baldeweg, T., Croft, R. J., Whittington, M., and Gruzelier, J. (2000). Gamma and beta frequency oscillations in response to novel auditory stimuli: a comparison of human electroencephalogram (EEG) data with in vitro models. Proc. Natl. Acad. Sci. U S A. 97, 7645-7650. doi: 10.1073/pnas.120162397

Hillstrom, A. P., and Chai, C. (2006). Factors that guide or disrupt attentive visual processing. Comp. Hum. Behav. 22, 648-656.

Holmqvist, K., Nyström, M., Andersson, R., Dewhurst, R., Jarodzka, H., and van de Weijer, J. (2017). Eye Tracking: A Comprehensive Guide to Methods and Measures. Oxford: Oxford University Press.

Hsieh, L. T., and Ranganath, C. (2014). Frontal midline theta oscillations during working memory maintenance and episodic encoding and retrieval. NeuroImage 85, 721-729. doi: 10.1016/j.neuroimage.2013.08.003

Huang, N. E., Shen, Z., Long, S. R., Wu, M. C., Shih, H. H., and Zheng, Q. (1998). The empirical mode decomposition and the Hilbert spectrum for nonlinear and non-stationary time series analysis. Proc. R. Soc. Mathemat. Phys. Eng. Sci. 454, 903-995. doi: 10.21105/joss.02977

Hyönä, J. (2010). The use of eye movements in the study of multimedia learning. Learn. Instruct. 20, 172-176. doi: 10.1016/j.learninstruc.2009.02.013

Itti, L., and Koch, C. (2000). A saliency-based mechanism for overt and covert shifts of visual attention. Vis. Res. 40, 1489-1506.

Jamet, E. (2014). An eye-tracking study of cueing effects in multimedia learning. Comp. Hum. Behav. 32, 47-53. doi: 10.3389/fpsyg.2020.592509

Jamet, E., Gavota, M., and Quaireau, C. (2008). Attention guiding in multimedia learning. Learn. Instruct. 18, 135-145.

Jarodzka, H., Scheiter, K., Gerjets, P., and Van Gog, T. (2010). In the eyes of the beholder: how experts and novices interpret dynamic stimuli. Learn. Instruct. 20, 146-154. doi: 10.1016/j.learninstruc.2009.02.019

Jasper, H. H. (1958). The ten-twenty electrode system of the international federation. Electroencephalogr. Clin. Neurophysiol. 10, 371-375.

Jeung, H. J., Chandler, P., and Sweller, J. (1997). The role of visual indicators in dual sensory mode instruction. Eduychology (Lond) 17, 329-345.

Jung, T. P., Makeig, S., Humphries, C., Lee, T. W., Mckeown, M. J., Iragui, V., et al. (2000). Removing electroencephalographic artifacts by blind source separation. Psychophysiology 37, 163-178. doi: 10.1111/1469-8986.3720163

Just, M. A., and Carpenter, P. A. (1976). Eye fixations and cognitive processes. Cognit. Psychol. 8, 441-480. doi: 10.1016/0010-0285(76)90015-3

Just, M. A., and Carpenter, P. A. (1980). A theory of reading: from eye fixations to comprehension. Psychol. Rev. 87, 329-354. doi: 10.1037/0033-295x.87.4.329

Kahana, M. J. (1996). Associative retrieval processes in free recall. Memory $\operatorname{Cogn}$. 24, 103-109. doi: 10.3758/bf03197276

Kahneman, D., and Beatty, J. (1966). Pupil diameter and load on memory. Science 154, 1583-1585. doi: 10.1126/science.154.3756.1583

Kahneman, D., and Beatty, J. (1967). Pupillary responses in a pitch discrimination task. Percept. Psychophys. 2, 101-105. doi: 10.3758/bf03210302

Kalyuga, S., Chandler, P., and Sweller, J. (1999). Managing split-attention and redundancy in multimedia instruction. Appl. Cogn. Psychol. 13, 351-371. doi: 10.1007/s10648-021-09606-9

Kalyuga, S., Chandler, P., and Sweller, J. (2000). Incorporating learner experience into the design of multimedia instruction. J. Educ. Psychol. 92, 126-136.

Kalyuga, S., and Sweller, J. (2005). Rapid dynamic assessment of expertise to improve the efficiency of adaptive e-learning. Educ. Technol. Res. Dev. 53, 83-93.

Khader, P. H., Jost, K., Ranganath, C., and Rösler, F. (2010). Theta and alpha oscillations during working-memory maintenance predict successful long-term memory encoding. Neurosci. Lett. 468, 339-343. doi: 10.1016/j.neulet.2009.11. 028

Klimesch, W. (1999). EEG alpha and theta oscillations reflect cognitive and memory performance: a review and analysis. Brain Res. Rev. 29, 169-195. doi: 10.1016/s0165-0173(98)00056-3

Klimesch, W. (2012). Alpha-band oscillations, attention, and controlled access to stored information. Trends Cogn. Sci. 16, 606-617. doi: 10.1016/j.tics.2012.10 007

Klimesch, W., Schack, B., and Sauseng, P. (2005). The functional significance of theta and upper alpha oscillations for working memory: a review. Exp. Psychol. 52, 99-108. doi: 10.1027/1618-3169.52.2.99

Kruger, J. L., and Doherty, S. (2016). Measuring cognitive load in the presence of educational video: towards a multimodal methodology. Australasian J. Educ. Technol. 32, 19-31.

Legesse, M., Luneta, K., and Ejigu, T. (2020). Analyzing the effects of mathematical discourse-based instruction on eleventh-grade students' procedural and 
conceptual understanding of probability and statistics. Stud. Educ. Eval. 67, $1-7$.

Lin, F. R., and Kao, C. M. (2018). Mental effort detection using EEG data in E-learning contexts. Comp. Educ. 122, 63-79. doi: 10.1016/j.compedu.2018.03. 020

Lin, J. J., Rugg, M., Das, S., Stein, J., Rizzuto, D., Kahana, M., et al. (2017). Theta band power increases in the posterior hippocampus predict successful episodic memory encoding in humans. Hippocampus 27, 1040-1053. doi: 10.1002/hipo. 22751

Mayer, R., and Fiorelle, L. (2014). Principles for Reducing Extraneous Processing in Multimedia Learning: Coherence, Signaling, Redundancy, Spatial Contiguity, and Temporal Contiguity Principles. Cambridge Handbook of Multimedia Learning, 2nd Edn. Cambridge: Cambridge University Press.

Mayer, R. E. (2005a). Cambridge Handbook of Multimedia Learning. New York, NY: Cambridge University Press.

Mayer, R. E. (2005b). “Cognitive theory of multimedia learning," in The Cambridge handbook of multimedia learning, ed. R. E. Mayer (New York, NY: Cambridge University Press), 31-48.

Mayer, R. E. (2014). "Cognitive theory of multimedia learning," in The Cambridge handbook of multimedia learning, 2nd Edn, ed. R. E. Mayer (New York, NY: Cambridge University Press), 31-48.

Mayer, R. E., and Chandler, P. (2001). When learning is just a click away: does simple user interaction foster deeper understanding of multimedia messages? J. Educ. Psychol. 93, 390-397.

Mayer, R. E., and Estrella, G. (2014). Benefits of emotional design in multimedia instruction. Learn. Instruct. 33, 12-18.

Mayer, R. E., and Moreno, R. (2003). Nine ways to reduce cognitive load in multimedia learning. Educ. Psychol. 38, 43-52. doi: 10.1207/s15326985ep3801_ 6

Miller, J., Watrous, A. J., Tsitsiklis, M., Lee, S. A., Sheth, S. A., Schevon, C. A., et al. (2018). Lateralized hippocampal oscillations underlie distinct aspects of human spatial memory and navigation. Nat. Commun. 9:2423.

Mutlu-Bayraktar, D., Coskun, V., and Altan, T. (2019). Cognitive load in multimedia learning environments: a systematic review. Comp. Educ. 141:103618. doi: 10.1016/j.compedu.2019.103618

Navalpakkam, V., Telang, S., and Itti, L. (2005). Attention can be guided to the relevant feature category. J. Vis. 5, 1007-1007. doi: 10.1167/5.8.1007

Ozcelik, E., Karakus, T., Kursun, E., and Cagiltay, K. (2009). An eye-tracking study of how color coding affects multimedia learning. Comp. Educ. 53, 445-453.

Paas, F., Renkl, A., and Sweller, J. (2003). Cognitive load theory and instructional design: recent developments. Educ. Psychol. 38, 1-4. doi: 10.1207/ s15326985ep3801_1

Paas, F., and Sweller, J. (2014). "Implications of cognitive load theory for multimedia learning," in The Cambridge Handbook of Multimedia Learning, 2nd Edn, ed. R. E. Mayer (Cambridge: Cambridge University Press), 27-42. doi: $10.1017 /$ cbo9781139547369.004

Paas, F. G., and van Merrienboer, J. J. (1993). The efficiency of instructional conditions: an approach to combine mental-effort and performance measures. Hum. Factors 35, 737-743. doi: 10.1177/001872089303500412

Paas, F. G., Van Merriënboer, J. J., and Adam, J. J. (1994). Measurement of cognitive load in instructional research. Perceptual Motor Skills 79, 419-430. doi: $10.2466 / \mathrm{pms}$.1994.79.1.419

Parbat, D., and Chakraborty, M. (2021). A novel methodology to study the cognitive load induced EEG complexity changes: chaos, fractal and entropy based approach. Biomed. Signal Proc. Control 64:102277. doi: 10.1016/j.bspc. 2020.102277

Park, B., Knörzer, L., Plass, J. L., and Brünken, R. (2015a). Emotional design and positive emotions in multimedia learning: an eyetracking study on the use of anthropomorphisms. Comp. Educ. 86, 30-42. doi: 10.1016/j.compedu.2015.02. 016

Park, B., Korbach, A., and Brünken, R. (2015b). Do learner characteristics moderate the seductive details-effect? a cognitive-load-study using eye tracking. Educ. Technol. Soc. 18, 24-36.

Pekrun, R. (2006). The control-value theory of achievement emotions: assumptions, corollaries, and implications for educational research and practice. Educ. Psychol. Rev. 18, 315-341. doi: 10.3109/0142159X.2012.64 3265
Penfield, W., and Jasper, H. (1954). Epilepsy and the Functional Anatomy of the Human Brain. Boston, MA: Little Brown.

Pi, Z. L., Zhang, L., Zhou, W. C., Xu, K., Chen, Y. R., Yang, J., et al. (2021). Learning by explaining to oneself and a peer enhances learners' theta and alpha oscillations while watching video lectures. Br. J. Educ. Technol. 52, 659-679.

Pincus, S. (1995). Approximate entropy (ApEn) as a complexity measure. Chaos 5, 110-117. doi: 10.1063/1.166092

Plass, J. L., Heidig, S., Hayward, E. O., Homer, B. D., and Um, E. (2014). Emotional design in multimedia learning: effects of shape and color on affect and learning. Learn. Instruct. 29, 128-140. doi: 10.1016/j.learninstruc.2013. 02.006

Raaijmakers, J. G. W., and Shiffrin, R. M. (1981). Search of associative memory. Psychol. Rev. 88, 93-134.

Rayner, K. (1998). Eye movements in reading and information processing: 20 years of research. Psychol. Bull. 124, 372-422. doi: 10.1037/0033-2909.124.3. 372

Richman, J. S., and Randall, M. J. (2000). Physiological time-series analysis using approximate entropy and sample entropy. AJP Heart Circulatory Physiol. 278, H2039-H2049.

Richter, J., Scheiter, K., and Eitel, A. (2016). Signaling text-picture relations in multimedia learning: a comprehensive meta-analysis. Educ. Res. Rev. 17, 19-36. doi: 10.1016/j.edurev.2015.12.003

Rosso, O. A., Blanco, S., Yordanova, J., Kolev, V., Figliola, A., Schurmann, M., et al. (2001). Wavelet entropy: a new tool for analysis of short duration brain electrical signals. J. Neurosci. Methods 105, 65-75. doi: 10.1016/s0165-0270(00) 00356-3

Scharinger, C., Schüler, A., and Gerjets, P. (2020). Using eye-tracking and EEG to study the mental processing demands during learning of text-picture combinations. Int. J. Psychophysiol. 158, 201-214. doi: 10.1016/j.ijpsycho.2020. 09.014

Schauss, A. G. (1979). Tranquilizing effect of color reduces aggressive behaviour and potential violence. J. Orthomol. Psychiatry 8, 218-220.

Schnotz, W. (2014). "An integrated model of text and picture comprehension," in The Cambridge Handbook of Multimedia Learning, 2nd Edn, ed. R. E. Mayer (Cambridge: Cambridge University Press), 49-69. doi: 10.1017/ cbo9780511816819.005

Seufert, T. (2003). Supporting coherence formation in learning from multiple representations. Learn. Instruct. 13, 227-237. doi: 10.1016/s0959-4752(02) 00022-1

Seufert, T., and Brünken, R. (2006). Cognitive load and the format of instructional aids for coherence formation. Appl. Cogn. Psychol. 20, 321-331. doi: 10.1002/ acp. 1248

Sghirripa, S., Graetz, L., Merkin, A., Rogasch, N. C., and Goldsworthy, M. R. (2020). Load-dependent modulation of alpha oscillations during working memory encoding and retention in young and older adults. Psychophysiology 58:e13719. doi: 10.1111/psyp.13719

Singer, W. (1993). Synchronization of cortical activity and its putative role in information processing and learning. Ann. Rev. Physiol. 55, 349-374. doi: 10.1146/annurev.ph.55.030193.002025

Soldat, A. S., Sinclair, R. C., and Mark, M. M. (1997). Color as an environmental processing cue: external affective cues can directly affect processing strategy without affecting mood. Soc. Cogn. 15, 55-71. doi: 10.1521/soco.1997. 15.1 .55

Solomon, E. A., Lega, B. C., Sperling, M. R., and Kahana, M. J. (2019). Hippocampal theta codes for distances in semantic and temporal spaces. Proc. Natl. Acad. Sci. U S A. 116, 24343-24352. doi: 10.1073/pnas.1906729116

Stark, L., Brünken, R., and Park, B. (2018). Emotional text design in multimedia learning: a mixed-methods study using eye tracking. Comp. Educ. J. 120, $185-196$.

Sterman, M. B., Mann, C. A., Kaiser, D. A., and Suyenobu, B. Y. (1994). Multiband topographic EEG analysis of a simulated visuomotor aviation task. Int. J. Psychophysiol. 16, 49-56. doi: 10.1016/0167-8760(94)90041-8

Sweller, J. (1988). Cognitive load during problem solving: effects on learning. Cogn. Sci. 12, 257-285. doi: 10.1207/s15516709 $\operatorname{cog} 1202 \_4$

Sweller, J. (1994). Cognitive load theory, learning difficulty and instructional design. Learn. Instruct. 4, 295-312. doi: 10.1016/0959-4752(94)90003-5 
Sweller, J. (2004). Instructional design consequences of an analogy between evolution by natural selection and human cognitive architecture. Instruct. Sci. $32,9-31$.

Sweller, J. (2010). Element interactivity and intrinsic, extraneous, and germane cognitive load. Educ. Psychol. Rev. 22, 123-138. doi: 10.3109/0142159X.2014. 889290

Sweller, J., van Merriënboer, J. J. G., and Paas, F. (2019). Cognitive architecture and instructional design: 20 years later. Educ. Psychol. Rev. 31, 261-292. doi: 10.1007/s10648-019-09465-5

Treisman, A. M., and Gelade, G. (1980). A feature-integration theory of attention. Cogn. Psychol. 12, 97-136.

Tuovinen, J. E., and Paas, F. (2004). Exploring multidimensional approaches to the efficiency of instructional conditions. Instruct. Sci. 32, 133-152. doi: 10.1186/ s12913-016-1423-5

van der Wel, P., and van Steenbergen, H. (2018). Pupil dilation as an index of effort in cognitive control tasks: a review. Psychon. Bull. Rev. 25, 2005-2015. doi: 10.3758/s13423-018-1432-y

van Gog, T. (2014). “The signaling (or Cueing) principle in multimedia learning," in The Cambridge handbook of multimedia learning, 2nd Edn, ed. R. E. Mayer (Cambridge: Cambridge University Press).

van Gog, T., and Scheiter, K. (2010). Eye tracking as a tool to study and enhance multimedia learning. Learn. Instr. 20, 95-99. doi: 10.1016/j.learninstruc.2009. 02.009

Wang, F. X., Zhao, T. T., Mayer, R. E., and Wang, Y. X. (2020). Guiding the learner's cognitive processing of a narrated animation. Learn. Instruct. 69:101357. doi: 10.1016/j.learninstruc.2020.101357
Wrobel, A. (2000). Beta activity: a carrier for visual attention. Acta Neurobiol. Exp. $60,247-260$.

Xie, H., Wang, F., Zhou, Z., and Wu, P. (2016). Cueing effect in multimedia learning: a meta-analysis. Acta Psychol. Sinica 48, 540-555. doi: 10.1371/ journal.pone.0183884

Yoshida, K., Hirai, F., and Miyaji, I. (2014). Learning system using simple electroencephalograph feedback effect during memory work. Proc. Comp. Sci. 35, 1596-1604. doi: 10.1016/j.procs.2014.08.243

Conflict of Interest: The authors declare that the research was conducted in the absence of any commercial or financial relationships that could be construed as a potential conflict of interest.

Publisher's Note: All claims expressed in this article are solely those of the authors and do not necessarily represent those of their affiliated organizations, or those of the publisher, the editors and the reviewers. Any product that may be evaluated in this article, or claim that may be made by its manufacturer, is not guaranteed or endorsed by the publisher.

Copyright (c) $2021 \mathrm{Liu}, \mathrm{Ma}, \mathrm{Guo}, \mathrm{Lin}, \mathrm{Wu}$ and Zhu. This is an open-access article distributed under the terms of the Creative Commons Attribution License (CC BY). The use, distribution or reproduction in other forums is permitted, provided the original author(s) and the copyright owner(s) are credited and that the original publication in this journal is cited, in accordance with accepted academic practice. No use, distribution or reproduction is permitted which does not comply with these terms. 